\title{
New combinations on Paratibraca Campos \& Grazia, 1995 (Hemiptera: Pentatomidae), with description of a new species
}

\author{
Jocelia Grazia $^{1 \pm=(\infty)}$, Kim R. Barão ${ }^{2 \oplus}$, Lurdiana D. Barros ${ }^{1 \oplus}$ \\ ${ }^{1}$ Universidade Federal do Rio Grande do Sul, Porto Alegre, RS, Brazil. ${ }^{2}$ Universidade Federal de Alagoas, Maceio, AL, Brazil.

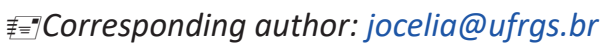

Edited by: Daniell R. R. Fernandes

Received: December 03, 2021. Accepted: December 22, 2021. Published: February 02, 2022.

Abstract. New combinations for Paratibraca amazonica (Gonçalves \& Campos, 2016) comb. n., Paratibraca dubia (Campos \& Souza, 2016) comb. n. and Paratibraca spinosa (Campos \& Grazia, 1998) comb. n. are proposed. Paratibraca rideri Barros, Barão \& Grazia sp. nov. from Brazil is described. Additions to the genus description, and photographs of type-specimens are provided.

Keywords: Mecocephala group, stink bug, Oriza sativa.

Paratibraca Campos \& Grazia, 1995 (Hemiptera: Pentatomidae) used to be a monotypic genus, included in the Mecocephala group (Carpocorini Mulsant \& Rey, 1866). The latter include many species of economic importance associated with rice crops (Barros et al. 2020a; 2020b). Because of the head and male genitalic morphologies Paratibraca have been associated with Hypatropis Bergroth, 1891, Mecocephala Dallas, 1851, Glyphepomis Berg, 1891, and Tibraca Stål, 1860. Morphological variation of male genitalia of Paratibraca infuscata Campos \& Grazia, 1995 is known for distinct populations (Campos \& Grazia 1995) highlighting male genitalic variation for this species or the necessity of better species delimitation. In the last two decades, Glyphepomis was revised and several species described, including Glyphepomis spinosa Campos \& Grazia, 1998 (Campos \& Grazia 1998), Glyphepomis amazonica Gonçalves \& Campos, 2016 and Glyphepomis dubia Campos \& Souza, 2016 (Bianchi et al. 2016). Detailed examination of the seven species currently included in Glyphepomis showed that G. amazonica, G. dubia and G. spinosa share diagnostics characters to the species included in Paratibraca, such as the outline of mandibular plates, form of bucculae, outline of anterolateral margins of pronotum, and genitalic characters of both sexes. Results of an ongoing study about the phylogenetic relationships within the Mecocephala group (Barros et al. in prep.) also suggested that those three species are more related to Paratibraca than to Glyphepomis. Here, we propose new combinations, describe a new species, and update the genitalic terminology for Paratibraca.

Type-material of all species included in Glyphepomis, Paratibraca, and allied genera were studied, from type specimens or images of type specimens. Types specimens of species treated here are deposited in either of these institutions: INPA-Instituto Nacional de Pesquisas da Amazônia, Manaus, Brazil; MZUSP-Museu de Zoologia da Universidade de São Paulo, São Paulo, Brazil; RMNH-Rijksmuseum van Natuurlijke Historie, Leiden, Netherlands; UFRG-Departamento de Zoologia, Universidade Federal do Rio Grande do Sul, Porto Alegre, Brazil; USNMNational Museum of Natural History, Washington D.C., United States. Preparation of the photographs, terminology of general and genitalic morphologies, as well as for the thoracic scent efferent system, follows Barros et al. (2021).

\section{Paratibraca Campos \& Grazia, 1995} Figs. 1A-C, 2A-K
Type-species. Paratibraca infuscata Campos \& Grazia, 1995, by monotypy.

Paratibraca Campos \& Grazia, 1995: 163-171, figs 1-15; Barros et al. 2020b: 321, 353-355, tabs. 1, 2.

Glyphepomis Berg, 1891 (partim); Campos \& Grazia 1998; 205-207, figs 1, 3-6, 19, 24-26, 36, 40; Bianchi et al. 2016: 445-450, figs 1-3, 5a-f, 6a-b, 7a, c, tab. 1.

Diagnosis. Anterolateral margins of pronotum flat; posterior margin of pronotum slightly convex, humeral angles produced, acute or rounded apically. Ostiole of external scent efferent system (ESES) elliptical; peritreme spout or bean-shaped; outer margin of metapleural evaporatorium convex or concave. Scutellum as wide as long. Apex of radial vein calloused. Spiracles not visible in abdominal sternite 2 . Superior layer of ventral rim covering parameres; lateral margin of each projection of superior layer of ventral rim of pygophore entire; ventral rim with one or a pair of processes, of variable size, visible in lateral view (Figs. $2 \mathrm{C}, 2 \mathrm{H}$ ), segment $\mathrm{X}$ quadrangular or rectangular. Processus capitati short or long in relation to phallotheca distal margin; conjunctiva with a pair of processes truncate apically, and lateral lobes present or not. Mesial margins of valvifers 8 reflected or not; posterior margins of valvifers 9 convex, with or without processes. Median wall of vesicular area cylindrical sub-proximally; ductus receptaculi into vesicular area rectilinear or coiled; distal ductus receptaculi short or long; diameter of anterior annular flange equal to pars intermedialis length; pars intermedialis enlarged or fanfolded.

Distribution. Panama (Chiriqui); Trinidad and Tobago (Curepe); Colombia (Meta, Tolima, Santander, and Valle del Cauca); Suriname (Clevia and Paramaribo); Brazil (Amazonas, Pará, Tocantins, Maranhão, Mato Grosso, Goiás, and São Paulo); Peru (Loreto) and Bolivia (Santa Cruz).

\section{Included species}

Paratibraca infuscata Campos \& Grazia, 1995: 165-171 [original description].

Paratibraca spinosa (Campos \& Grazia, 1998) comb. n. (Fig. 1A). Glyphepomis spinosus Campos \& Grazia, 1998: 205-207 [original description].

Paratibraca dubia (Campos \& Souza, 2016) comb. n. (Fig. 1B). Glyphepomis dubia Campos \& Souza, 2016: 445-447 [original description]. 

1C).

Paratibraca amazonica (Gonçalves \& Campos, 2016) comb. n. (Fig.

Glyphepomis amazonica Gonçalves \& Campos, 2016: 447450 [original description].

Paratibraca rideri Barros, Barão \& Grazia sp. nov. (Fig. 2).

Paratibraca rideri Barros, Barão \& Grazia sp. nov. urn:Isid:zoobank.org:act:65156A8C-26D0-434C-8EAB-186C9345E4C4 Fig. 2A-K

Type material. Holotype: + , Brazil, Pará, Santarém, 17-26.I.2016,

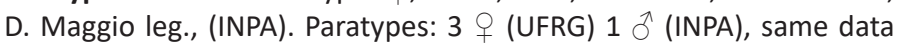
as holotype.

Etymology. This species is dedicated to David Rider in recognition of his great contribution to the knowledge of heteropteran systematics.

Diagnosis. Relatively larger than other congeners (see Measurements), general body color light brown dorsally and dark brown ventrally, humeral angles produced and rounded apically, the pygophore trapezoidal, with posterolateral angles rounded, opening of genital cup broad, and inferior layer produced, the posterior margins of valviferes 9 convex and laterotergites 9 longer than valvifers 8 .

Description. General colour light brown dorsally; ventral surface dark brown; body densely punctate with dark punctures. Ocelli red. Antennomere 4 and 5 mostly dark brown. Callosity of radial vein concolor with surface of hemelytra. Pro, meso, metasternum and evaporatorium dark-brown; peritreme of ESES light brown. Legs light brown, with dark spots. Body oval. Dorsal and ventral surface of body convex (Fig. 2C). Head longer than wide (Fig. 2D). Mandibular plates rounded apically, shorter than clypeus; outer margins of mandibular plates sinuous and lower than inner margins. Clypeus narrower basally than apically, apex obtuse; clypeus in a higher level than mandibular plates in lateral view; clypeal suture beginning after an imaginary line crossing anterior margin of compound eyes. Antenniferous tubercles visibles in dorsal view, each with an obtuse process laterally. Proportions of antennomeres: $1>2<3>4<5$. Antennomere 1 not reaching apex of head; antennomere 3 cylindrical; antennomere 4 conical, slightly flattened dorsally, slightly grooved dorsally. Bucculae rectilinear, tapering toward base of the head, not reaching its base. Labium reaching abdominal sternite 3 medially (Fig. 2B). First labiomere contained between bucculae. Pronotum trapezoidal; each anterior angle of pronotum with an obtuse process directed laterally; anterolateral margins of pronotum concave, flat and smooth; humeral angles produced, rounded apically; posterolateral margins of pronotum sinuous; posterior margin of pronotum slightly convex (Fig. 2D). Mesosternal carina slightly elevated and smooth. Metasternum with a shallow groove. Ostiole of ESES elliptical, opening posterolaterally; periostiolar depression present; each ostiolar peritreme spout-shaped, long, occupying half of the distance to lateral margin of evaporatorium. Evaporatorium punctate, occupying more than half of the width of meso and metapleuron. Anterolateral margins of metapleural evaporatorium rounded. Evaporatorium on mesopleuron surpassing the limits of mesocoxal sutures, reaching its anterior and posterior lateral angles, and the outer margin (Fig. 2E). Metathoracic spiracle wide. Femora subequal than tibiae in length. Tarsi 3-segmented. Scutellum longer than wide (Fig. 2A); apex rounded, surpassing the posterior margin of the abdominal tergite 5 . Basal angles of scutellum with foveae smaller than the diameter of a compound eye. Corium longer than scutellum, surpassing apices of abdominal tergite 5; apex of radial vein calloused; veins of membrane linear. Membranal suture sinuous. Apex of hemelytra not surpassing apex of body. Connexivum exposed (Fig. 2A). Posterolateral angles of sternites unarmed, straight. Callus mesial to each spiracle (Fig. 2C).

Male genitalia. (Figs. 2F-H). Genital cup of pygophore broad, opened dorsoposteriorly, and occupying more than half the length of pygophore. Middle region of dorsal rim entire, and extension of dorsal rim not produced (Fig. 2F). Layers of ventral rim not separated by a carina; area between layers depressed and striated (Fig. 2G). Superior layer of ventral rim projected over genital cup, developed laterally to segment $X$, covering parameres; lateral margins of superior layer of ventral rim entire, in caudal view; with a pair of superior processes.

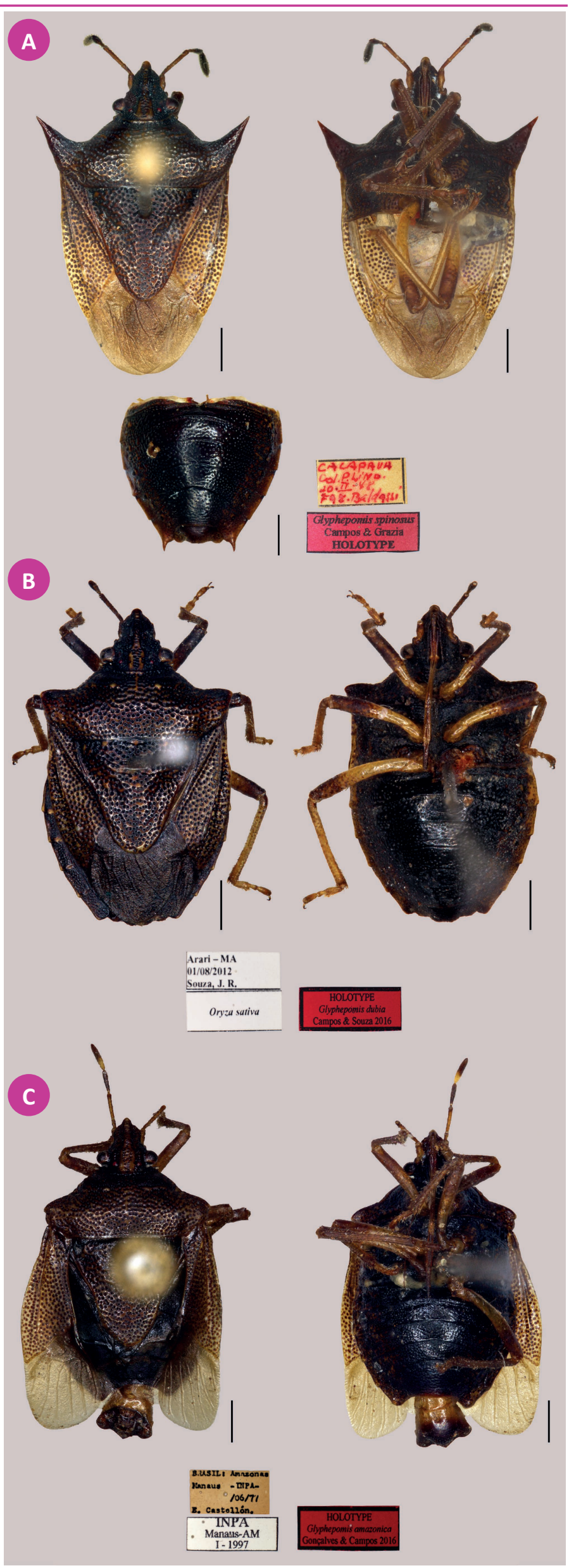

Figure 1. Dorsal and ventral habitus of holotypes of Paratibraca species. A-Paratibraca spinosa comb. n.; B-Paratibraca dubia comb. n.; C-Paratibraca amazonica comb. $\mathbf{n}$.. 
Inferior layer of ventral rim with a pair of processes (Fig. 2H). Segment $\mathrm{X}$ rectangular, not carinate, without processes. Parameres present, crown reduced. The male genitalia was not dissected because this species is represented by a single male specimen.

Female genitalia. Valvifers 8 flat, sub equal to valvifers 9 in length, partially covering valvifers 9 , mesial margins juxtaposed, posterior margins sinuous. Valvulae 8 not visible externally (Figs. 2l-J). Valvifers 9 depressed, leveled to segment $X$, with esclerotized lateral arms attaining anterior margins of laterotergites 9 , anterior margins straight, posterior margins convex. Laterotergites 9 surpassing abdominal tergite 8, mesial margins divergent, posterior margins obtusely projected. Valvulae 9 with $1+1$ medially sclerotized areas (Fig. $2 \mathrm{~K}$ ). Ring sclerites elliptical. Arcuate posterior portion of thickening of vaginal intima longer than the round anterior portion. Median wall of vesicular area cylindrical subproximally. Proximal ductus receptaculi long in relation to length of vesicular area, twisted, and diameter equal and aspect straight into vesicular area. Distal ductus receptaculi short in relation to vesicular area, twisted. Annular flanges parallel to each other, diameter of anterior annular flange equal to pars intermedialis length and posterior annular flange wider than capsula seminalis. Pars intermedialis fanfolded. Capsula seminalis globose and shorter than the pars intermedialis (Fig. 2K).

Measurements (mean \pm standard deviation, $\mathrm{mm}$ ). Total length: $11.12 \pm 2.32$; Abdominal width: $6.96 \pm 1.16$; Head. length: $2.15 \pm 0.13$; width: $1.92 \pm 0.07$; Interocular distance: $1.10 \pm 0.04$; Clypeus length: $1.23 \pm 0.03$; Antennomeres. 1 : $0.59 \pm 0.04$; 2 : $0.47 \pm 0.03$; 3: $1.18 \pm$



Figure 2. Paratibraca rideri sp. nov.. A-B-Habitus in dorsal and ventral views of holotype; C-habitus lateral of male, paratype; D-Head and pronotum of holotype; E-evaporatorium of holotype; F-H-Pygophore in dorsal, posterior and ventral view of male paratype; I-J-Genital plates in lateral and posteroventral views of holotype; K-Female receptaculum seminis and aussenwand of female paratype. Scale bars = A-C: $1.0 \mathrm{~mm}$; D-K: $0.5 \mathrm{~mm}$. Abbreviations: aaf-anterior annular flanges; alvr-area between layers of ventral rim; ddr-distal ductus receptaculi; dr-dorsal rim; ev-evaporatorium; ilvr-inferior layer of ventral rim of pygophore; la8-laterotergites 8; la9-laterotergites 9; ms-mesopleuron; mt-metapleuron; paf-posterior annular flange; pdr-proximal ductus receptaculi; pi-pars intermedialis; pilvr-process of inferior layer of ventral rim; pslvr-process of superior layer of ventral rim; rs-ring sclerites; slvr-superior layer of ventral rim of pygophore; tvi-thickening of vaginal intima; va-vesicular area; vf8-valvifers 8; vf9-valvifers 9; vr-ventral rim; $x$-segment $X$. 
0.04; 4: $0.86 \pm 0.03 ; 5: 1.09 \pm 0.03$; Labiomeres. 1: $0.94 \pm 0.12 ; 2: 1.57$ $\pm 0.16 ; 3: 1.11 \pm 0.03 ; 4: 0.85 \pm 0.04$; Pronotum. length: $2.35 \pm 0.18$ width: $5.53 \pm 0.41$; Scutellum. length: $3.69 \pm 0.20$; width: $3.80 \pm 0.19$.

Distribution. Brazil (Pará).

Comments. Paratibraca rideri sp. nov. and $P$. infuscata share similar dorsal facies, peritreme spout and long, anterolateral margins of metapleural evaporatorium rounded, dorsal rim of pygophore with marginal processes, inferior layer of ventral rim of pygophore with a pair of processes, segment $X$ without processes, and the annular flanges wider and pars intermedialis fanfolded; in the other congeners the pars intermedialis is enlarged. The remarkable character shared by both species with $P$. dubia and $P$. spinosa is the distal ductus receptaculi twisted and short. $P$. rideri and $P$. amazonica can be easily distinguished because the latter is the smallest of the species and present the genitalic morphology of both sexes different from its congeners, such as: inferior layer of ventral rim of pygophore with one process; phallic characters; ductus receptaculi narrower, long and coiled in and out the vesicular area.

\section{Taxonomic Authorities}

Carpocorini Mulsant \& Rey, 1866 in Mulsant \& Rey (1866). Glyphepomis Berg, 1891 in Berg (1891). Glyphepomis amazonica Gonçalves \& Campos, 2016 in Bianchi et al. (2016). Glyphepomis dubia Campos \& Souza, 2016 in Bianchi et al. (2016). Glyphepomis spinosus Campos \& Grazia, 1998 in Campos \& Grazia (1998). Hypatropis Bergroth, 1891 in Bergroth (1891). Mecocephala Dallas, 1851 in Dallas (1851). Paratibraca Campos \& Grazia, 1995 in Campos \& Grazia (1995). Paratibraca infuscata Campos \& Grazia, 1995 in Campos \& Grazia (1995). Tibraca Stål, 1860 in Stål (1860).

\section{Acknowledgments}

We are grateful to the curators of the listed collections for the loaning of specimens. We also thank the value contributions of the reviewer which improved the paper. This study was financed in part by the Coordenação de Aperfeiçoamento de Pessoal de Nível SuperiorBrasil (CAPES)-Finance Code 001-as a Doctoral Scholarship granted to LDB. JG is supported by Conselho Nacional de Desenvolvimento Científico e Tecnológico-Brasil (CNPq) with a fellowship grant (PQ \#310747/2020-1).

\section{Authors' Contributions}

All authors contributed to the writing and reviewing of this work.

\section{Conflict of Interest Statement}

No potential conflict of interest was reported by the authors.

\section{References}

Barros, L. D.; Barão, K. R.; Grazia J. (2020a) The genus Parahypatropis Grazia \& Fernandes, with description of two new species and description of a new similar monotypic genus (Hemiptera: Pentatomidae). Journal of Natural History, 54(15/16): 1045-1071. doi: 10.1080/00222933.2020.1781274

Barros, L. D., Barão, K. R.; Grazia, J. (2020b) Systematics of the Mecocephala group (Hemiptera: Heteroptera: Pentatomidae) based on a phylogenetic perspective: Inclusion of Hypanthracos, description of three new genera, and redescription of Ogmocoris. Arthropod Systematics \& Phylogeny, 78(2): 321-360. doi: 10.26049/ ASP78-2-2020-07

Barros, L. D., Barão, K. R.; Grazia, J. (2021) Taxonomic updates on the Mecocephala group (Hemiptera: Pentatomidae): Redescription of 'Hypatropis complex', with a review of genitalic terminology and new records. Zootaxa, 4981(1): 001-046. doi: 10.11646/ zootaxa.4981.1.1

Berg, C. (1891) Nova Hemiptera Faunarum Argentinae et Uruguayensis.
Anales de la Sociedad Científica Argentina, 32, 280-282.

Bergroth, E. (1891) Contributions a 1' étude des pentatomides II. Espèces du nouveaux monde. Revue d'Entomologie, 10, 214-235.

Bianchi, F. M.; Gonçalves, V. R.; Souza, J. R.; Campos, L.A. (2016) Description of three new species of Glyphepomis Berg (Heteroptera: Pentatomidae: Pentatominae). Zootaxa, 4103(5): 443-452. doi: 10.11646/zootaxa.4103.5.2

Campos, L. A.; Grazia, J. (1995) Paratibraca, um novo gênero de Pentatomini (Heteroptera: Pentatomidae). Iheringia, Série Zoologia, 79: 163-171.

Campos, L. A.; Grazia, J. (1998) Revisão de Glyphepomis Berg, 1891 (Heteroptera: Pentatomidae). Revista Brasileira de Entomologia, 41: 203-212.

Dallas, W. S. (1851) List of the specimens of hemipterous insects in the collection of the British Museum. In: Gray, J. E. (ed.) British Museum (Natural History). London I, p. 390, 15 pls. doi: 10.5962/ bhl.title.20373

Mulsant, E. M.; Rey, C. (1866) Historie Naturelle de Punaises de France. In: Annales de la Société Linnéenne de Lyon, tome 13, Année 1866, Paris, 112pp. doi: 10.3406/linly.1866.3943

Stål, C. (1860) Bidrag till Rio de Janeiro-traktens Hemipter-fauna. Kongliga Svenska Vetenskaps-Akademiens Handlingar, 2(7): 1-84. 